\title{
RESULTS OF TREATMENT OF PLICA SYNDROME OF THE KNEE
}

\section{RESULTADOS DO TRATAMENTO DA PREGA SINOVIAL (PLICA) PATOLÓGICA DO JOELHO}

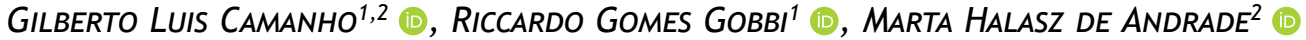 \\ 1. Universidade de São Paulo, Medical School, Hospital das Clínicas, Orthopedics and Traumatology Institute, São Paulo, SP, Brazil. \\ 2. Instituto Ortopédico Camanho, São Paulo, SP, Brazil.
}

\section{ABSTRACT}

Objective: The synovial fold is an intra-articular structure found in more than $50 \%$ of the knees, which can cause symptoms similar to meniscal injuries. These symptoms are mostly related to hypertrophy of the synovial fold resulting from inadequate physical activity. Conservative treatment with readjustment of sports activity and muscle rebalancing solves most cases. Rare cases require surgical treatment, which is indicated due to the persistence of instability, blockage and pain. We present our experience in the treatment of this pathology. Methods: 58 patients (70 knees), with 62 knees treated conservatively and 8 treated surgically exclusively for the pathological synovial fold. Results: Description of the series and treatment results are reported. Conclusion: The non-surgical treatment of the pathological synovial fold of the knee provided good results within 60 days of rehabilitation program in almost $90 \%$ of the patients. Arthroscopic resection of the synovial fold is a surgery that has a longer and laborious rehabilitation period, despite good results in most cases. Level of Evidence IV, Case series.

\section{RESUMO}

Objetivo: A prega sinovial é uma estrutura intra-articular encontrada em mais de 50\% dos joelhos, que pode provocar sintomas semelhantes aos da lesão meniscal. Esses sintomas estão relacionados, na maioria dos casos, à hipertrofia da prega sinovial decorrente de atividade física inadequada. O tratamento conservador com a readequação da atividade esportiva e reequilíbrio muscular resolve a maioria dos casos. Raros casos demandam tratamento cirúrgico, que é indicado pela persistência de falseios, bloqueios e dor. Apresentamos nossa experiência no tratamento dessa patologia. Métodos: 58 pacientes (70 joelhos), com 62 joelhos tratados conservadoramente e 8 tratados cirurgicamente exclusivamente para a prega sinovial patológica. Resultados: São apresentados descrição da série e resultados do tratamento. Conclusão: O tratamento não cirúrgico da prega sinovial patológica do joelho propiciou bons resultados com 60 dias de programa de reabilitação em quase $90 \%$ dos pacientes. A ressecção artroscópica da prega sinovial é uma cirurgia que tem um período de reabilitação mais longo e trabalhoso, apesar do bom resultado na maioria dos casos. Nível de Evidência IV, Série de casos.

Keywords: Knee. Synovitis. Synovial Folds.

Descritores: Joelho. Sinovite. Pregas Sinoviais.

Citation: Camanho GL, Gobbi RG, Andrade MH. Results of treatment of plica syndrome of the knee. Acta Ortop Bras. [online]. 2021;29(2):72-75. Available from URL: http://www.scielo.br/aob.

\section{INTRODUCTION}

Synovial plica, as it is known in the orthopedics, is called "synovial fold" in the anatomy. Its asymptomatic presence is frequent, and its prevalence can reach $50 \%$, according to postmortem and arthroscopic anatomical studies. ${ }^{1}$ It is an important cause of diagnostic failure, since it can cause symptoms similar to meniscal injury, usually without a history of trauma, being directly related to inadequate physical activity that can lead to hypertrophy of the synovial fold. It can be present in several possible locations, the most frequent being the infrapatellar (mucous ligament), followed by the suprapatellar and mediopatellar. ${ }^{2,3}$ Medial localization is the most clinically relevant, because its thickening caused by trauma, repetitive exertion and other conditions causes marginal synovial irritation in the femoral medial condyle and patella, causing synovitis and even chondral injury. This clinical situation is known as synovial fold (or plica) syndrome. ${ }^{4}$ Magnetic resonance imaging (MRI) helps a lot in its identification, but it often goes unnoticed by the radiologist and should be actively sought according to clinical suspicion (Figure 1).

All authors declare no potential conflict of interest related to this article. 


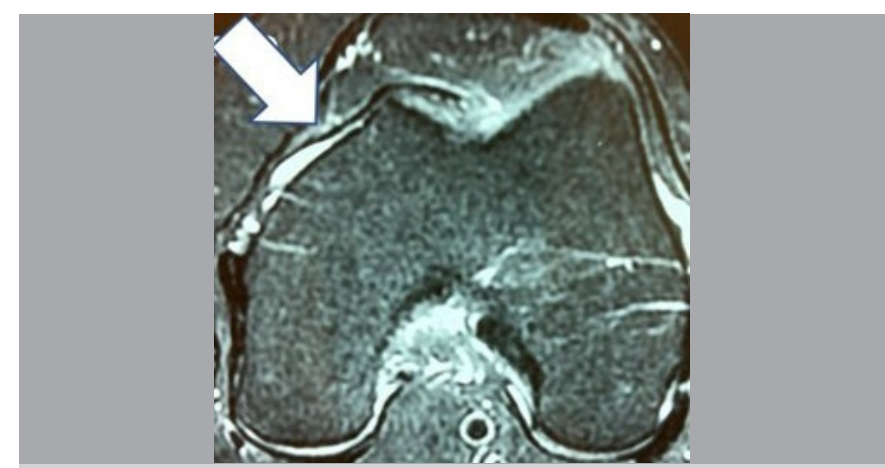

Figure 1. Resonance of the knee showing synovial fold interposed between the articular face of the patella and the medial femoral condyle in axial projection.

Pathological folds cause symptoms such as pain after physical activity, blockages, instability (giving way) and possible effusions. Conservative treatment with the readjustment of sports activity and muscle rebalance is the first-line treatment and solves most cases. Surgical treatment with synovial fold resection is indicated in cases of persistence of mechanical phenomena (instability and blockage) and pain, after a satisfactory program of physiotherapy and adjustments in physical activity.

We describe the evolution of 50 patients (62 knees) treated with physiotherapy and re-education of physical activity and 8 surgically treated patients in the last 10 years.

\section{MATERIALS AND METHODS}

Patients treated by the authors in the last 10 years due to pathological synovial fold were included, with a diagnosis made by the clinical presentation and confirmed by magnetic resonance imaging. Ethics committee approval 78967517.0.0000.0068, obtained waiver from the informed consent form.

The most frequent clinical presentation consists of onset of blocking symptoms and pain to the final extension of the knee, with the quadriceps contracted, after a modification of sports activity, even in athletes. Compression of the medial edge of the patella (taking care not to generate increased carytillanous pressure) associated with quadriceps contraction, with the knee in extension causes pain by favoring the clamping of the plica between the patella and the femur.

The cases of patients with synovial folds visualized and treated in other associated surgical procedures and patients that did not undergo an adequate minimum program of 10 physiotherapy sessions were excluded, as well as patients with previous knee surgeries.

We used the lino classification, since it was the one adopted in our study of incidence of synovial fold in 100 knees (1). lino published his Japanese language classification, and the synovial fold also came to be known as "lino's band." 5 type A - a medial synovial thickening, with a cord aspect, which descends through the medial synovial, originating at the level of the upper pole of the patella, to insert itself in the infrapatellar fatty cushion; type B - a strip of synovial membrane with laminar aspect, similar to a "windsurfing sail" and running through the medial synovial, from the infrapatellar cushion to immediately below the suprapatellar pouch, inserting itself in the suprapatellar fold, as a continuation of or close to it; type C - similar to type B, usually larger, wider, thicker and covering part of the medial femoral condyle, scraping against it and the medial articular face of the patella to knee joint movements; type D - rare variety, is a fold with double proximal insertion, forming a "false bucket handle," which can be interspersed with the patellofemoral joint.
Conservative physical therapy treatment consisted of a stretching program and strengthening of specific muscle groups, and reeducation for sports activity was based on the skills and physical conditions of the patients. Special attention was paid to the knee joint muscle (articularisgenus) that tensions the capsule and synovial of the knee avoiding its clamping, ${ }^{6}$ stimulated in the adequacy of quadriceps extensor function in knee hyperextension exercises. The program has been used for years after satisfactory previous results. ${ }^{7}$

Cases refractory to physical therapy treatment were indicated for surgery if symptoms were maintained for $>3$ months. The operation, when necessary, consisted of synovectomy with extensive resection of the synovial fold, performed arthroscopically, ${ }^{8}$ using a $4.5 \mathrm{~mm}$ or $5.0 \mathrm{~mm}$ "shaver" blade.

After surgery, the patients were discharged on the same day of the operation and started rehabilitation within 7 days, aiming at regaining movement and restoring muscle strength.

After treatment, patients were followed up by the authors in evaluations at 2, 4 and 12 months. We analyzed the return of patients to their non-sports activities, the presence or absence of pain, the return of the normal knee range of motion, the presence or absence of blocking sensation, and the recovery of muscle strength as the objective of treatment.

\section{RESULTS}

Fifty-eight patients with 12 bilateral cases were included, which determined a n of 70 knees. Age ranged from 14 to 52 years, with a mean of 28.5 and median of 26 years.

The right side was affected in 38 knees (51\%), and 38 patients (76\%) were female.

Clinically, all patients complained of pain after sports activity and the sensation of joint blockage. Joint effusion has been reported only by 14 patients.

All patients were first treated conservatively. Of these, 50 patients (86\%) improved and did not require surgery, with 12 bilateral cases totaling 62 knees treated by rehabilitation (7). Of this group, 34 were female (68\%) and only 5 patients (10\%) did not improve within 2 months of rehabilitation. At 4 months and 1 year, all patients were healthy.

Among the 8 patients that did not improve up to 4 months and consequently received surgical indication, all had the unilateral condition, and the right side was affected in 5 cases, and 3 were female (37.5\%). Age ranged from 23 to 41 years, with a mean of 26 years. We could only classify the folds of the operated cases, since they were visualized during arthroscopy, being 6 synovial folds of type $\mathrm{C}$ and 2 of type $\mathrm{D}$ of lino.

During arthroscopy, 7 cases (87.5\%) presented chondral lesion due to friction, 3 in the medial femoral condyle and 4 in the patella (Figure 2). The exposure of the subcondral bone was not observed in any case.

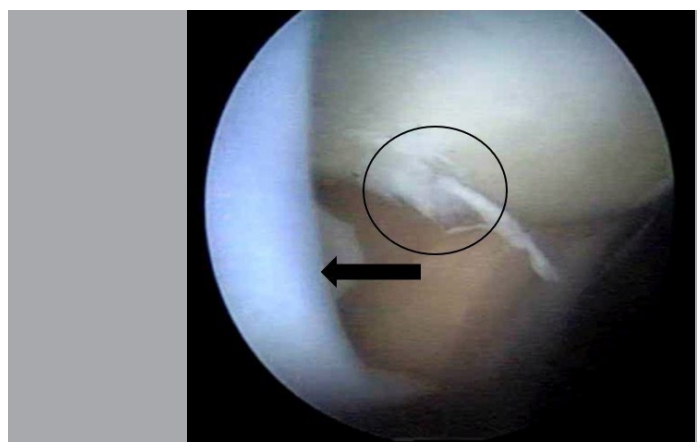

Figure 2. Image obtained arthroscopically of pathological mediopatellar fold (arrow). The medial articular face of the patella with lesion in the area of contact with the fold (circle) is noted. 
After 60 days of postoperative evolution, of the 8 operated patients 2 were discharged and 6 (four men) had delayed results represented by pain (in the 6 cases), quadriceps insufficiency (in the 6 cases) and joint limitation (in 3 cases). Of these, 3 patients were discharged with satisfactory treatment before the 6th postoperative month; among these were the 2 type $\mathrm{D}$ cases of lino. Two patients prolonged their rehabilitation up to 6 months with improvement, and 1 patient abandoned our treatment at 5 months still with complaints.

After 1 year, 7 patients completed the evaluation period. Seven were asymptomatic and only one patient (who abandoned treatment at 5 months) complained of lack of strength in the operated limb and maintenance of pain.

Of the 14 patients with joint effusion, 10 were from the conservative treatment group and no longer had the presence of effusion after 1 year of follow-up. Of the 4 patients with joint effusion treated surgically, 3 had a chondral lesion.

\section{DISCUSSION}

The main finding of our study is that conservative treatment is most often successful for knee synovial fold syndrome, with $88 \%$ resolution of symptoms. Refractory cases showed an improvement of $87.5 \%$ with surgical treatment. Only 1 operated patient did not progress satisfactorily after a 12-month follow-up.

The experience of the authors is that most patients improve complaints only with general guidance and stretching, without the need for a structured rehabilitation program. The patients, once oriented, do their stretching and adapt to the sports activity, living well with the synovious folds. The 58 patients included in this study are an exception and required structured physical therapy follow-up. Conservative treatment is a consensus. The surgical indication is exceptional, only in cases that did not obtain results of conservative treatment and with more evident mechanical complaints, representing approximately only $0.25 \%$ of all surgeries performed by the authors in the last 10 years.

Most patients are practicing some physical activity. Kang et al., 9 found the presence of synovial fold of increased size in $38 \%$ of soldiers with anterior knee pain. They verified that the clinical examination associated with MRI has high accuracy in the diagnosis of synovial fold, and also report the ultrasound value. We have no experience with the use of ultrasound.

Our group studied in two opportunities the incidence of synovial folds in cadavers, according to each type..$^{1,10}$ Older et al. ${ }^{10}$ found, in 115 dissections, 47 medial folds (41\%), 10 type A of lino, 29 of type B, 8 of type $\mathrm{C}$ and no type D. Joyce III et al., ${ }^{11}$ in 492 dissections of the knees of cadavers, found medial synovial fold in $47 \%$ of the times. In this series, we operated 6 folds of type $C$ of lino and 2 of type $D$. Perhaps the rarest types $C$ and $D$ are of worse evolution and present greater need for surgery, but our sample does not allow this conclusion, since it is not possible to correctly classify the fold without arthroscopy in patients treated conservatively.

The occurrence of associated lesions is controversial in the literature. Hardaker et al., ${ }^{12}$ found synovitis and erosion of the cartilage of the condiles in 37 knees and chondromalacia of the patella in 35 out of 53 arthroscopies. In 22 knees, there was the presence of the medial suprapatellar fold; in five, the medial and lateral suprapatellar fold, and in 15 , of the medial synovial fold associated with the medial suprapatellar fold. Munzinger et al., found 61 medial synovial folds in 136 arthroscopies. ${ }^{13}$ In five, there was chondromalacia of the patella in the contact area of the fold; in three, cartilaginous alteration in the medial femoral condyle; and, in two, alterations in both the patella and the condyle. In another study of 174 medial synovial folds, found in arthroscopies performed by Vielpeau et al., the authors report that 134 patients had patellar chondrosis, 43 had inflammatory chondral lesion in the medial femoral condyle and 14 in the lateral. ${ }^{14}$ Cohen et al., ${ }^{15}$ out of 74 arthroscopies of symptomatic medial folds, found 31 associated lesions, of which 13 were articular cartilage injury, seven medial meniscopathies, five lateral and in four anterior cruciate ligament injuries. However, meniscal and ligament injuries do not seem to be related to the presence of the medial synovial fold.

All these authors treated folds concomitant with other knee pathologies. In this series, we include only cases with clinical diagnosis and confirmed by MRI of pathological synovial fold alone, without other associated pathology. We found three femoral and four patellar lesions, without full-thickness lesions. Three of these patients presented joint effusion, a frequent fact in patients with these cartilage lesions.

The expectation with the resection of the plica is to offer rapid improvement and a satisfactory rehabilitation within 60 days. However, it was not effective; the surgery did not offer patients a rapid rehabilitation such as plica cases that responded well to conservative treatment. The presence of pain and difficulty in activating the quadriceps were the major complaints. This limitation occurred in 6 of the 8 (75\%) patients operated on the first 2 months. We could not relate this initial difficulty of rehabilitation to any of the demographic data or to associated injuries found due to the small number of cases. As described in the results, only 1 patient had not improved at 1 year, so knee surgeons should not expect a postoperative and rehabilitation as fast as a meniscectomy, for example.

Hufeland and al. operated 35 young patients with synovial plica, with clinical diagnosis and MRI. They report good results, with return of all patients to the activity that preceded the surgery. ${ }^{16}$ Wecksttröm et al. ${ }^{17}$ report experience of 23 patients undergoing arthroscopic surgical resection of synovial plicas. The follow-up was long, above 5 years, and the results were good in $74 \%$.

Schindler, in an extensive literature review, states that the results of the few operated cases are good in $64 \%$. The author's study is based on a meta-analysis of 969 cases of 23 studies. The profile of patients is very similar to ours, with young patients, mean age of 25 years, with a mean follow-up of 26 months. ${ }^{18}$ Good results of only $64 \%$ are below most knee surgeries, and therefore the origin of pain as being of plica should be considered as an exception, and the surgical procedure should be restricted to cases actually refractory to conservative treatment. Resection of the synovial plica should not be considered a trivial and rapid rehabilitation surgery.

The greatest limitations of our study are its retrospective nature, although all were followed by the senior author and the data are reliable. Moreover, the low number of operated cases made us avoid statistical analyses, and choose to report the experience in these patients descriptively. In any case, our study presents a significant number of cases with synovial plica, interestingly exemplifying what knee surgeons should expect from their specific treatment. Synovial folds must be further studied, since they may have other functions, perhaps due to its innervation, and not consider them only structures that can impinge in physical activities and as sources of pain. Moreover, a systematization of MRI interpretation may help to better classify them.

\section{CONCLUSION}

Non-surgical treatment of pathological knee synovial fold provided good results with 60 days of rehabilitation program in almost $90 \%$ of patients. Arthroscopic resection of the synovial fold is a surgery that has a longer and laborious rehabilitation period, despite the good results in most cases. 
AUTHORS' CONTRIBUTIONS: Each author contributed individually and significantly to the development of this article. GLC: writing of the article, review and performance of surgeries; RGG: data analysis and writing of the article; MHA: rehabilitation and review of the article.

\section{REFERENCES}

1. Cardoso TP, Camanho GL. Incidência da prega sinovial medial do joelho: estudo em cadáveres. Rev Bras Ortop. 1996;31(2):169-74.

2. Jouanin T, Dupont JY, Halimi P, Lassau JP. The synovial folds of the knee joint: anatomical study. Anat Clin. 1982;4:47-53.

3. Boles CA, Martin DF. Synovial plicae in the knee. AJR Am J Roentgenol 2001;177:221-7.

4. Jee WH, Choe BY, Kim JM, Song HH, Choi KH. The plica syndrome: diagnostic value of MRI with arthroscopic correlation. J Comput Assist Tomogr. 1998;22(5):814-8.

5. Lino S. Normal arthroscopic findings of the knee joint in adult cadavers. J Jpn Orthop Assoc. 1939;14:467-523.

6. Ahmad I. Articular muscle of the knee: articularis genus. Bull Hosp Joint Dis. 1975;36(1):58-60

7. Amatuzzi MM, Fazzi A, Varella MH, Dornelas CB. Plica sinovial patológica do joelho. Diagnóstico e resultado do tratamento conservador em 101 casos. Rev Bras Ortop. 1987;22(1):9-15.

8. Koshino T, Okamoto R. Resection of painful shelf (plica synovialis mediopatellaris) under arthroscopy. Arthroscopy. 1985;1(2):136-41.

9. Kang S; Park J; Kang SB; Chang CB. MRI findings of young male soldiers with atraumatic anterior knee pain. Scand J Med Sci Sports. 2016;26(5):572-8.

10. Older J, Hanspal R, Cardoso T. The medial shelf: an anatomical, clinical and pathological study. In: Trickey EL, Hertel P, editors. Surgery and arthroscopy of the knee. Berlin: Springer; 1986. p. 82-6.
11. Joyce JJ 3rd, Harty M, Tezlaff JR. Surgery of the synovial folds. In: Casscells SW, editor. Arthroscopy: diagnostic and surgical practice. Philadelphia: Lea \& Febiger; 1984. p. 94-9

12. Hardaker WT, Whipple TL, Basset FH 3rd. Diagnosis and treatment of the plica syndrome of the knee. J Bone Joint Surg Am. 1980;62(2):221-5.

13. Munzinger U, Ruckstuhl J, Scherrer H, Gschwend N. Internal derangement of the knee joint due to pathological synovial folds: the mediopatellar plica syndrome. Clin Orthop Relat Res. 1981;(155):59-62.

14. Vielpeau C, Beguin J, Aubriot JH, Locker B, Heron JF, Sabatier JP. [Place of the medio-patellar plica in the pathology of the knee. Report on 172 cases (author's transl)]. Ann Chir. 1981; 34:325-31.

15. Cohen M, Abdalla RJ, Queiroz AAB, Saone R. Estudo artroscópico da prega sinovial sintomática do joelho. Rev Bras Ortop. 1987;22(10):293-6.

16. Hufeland M, Treder L, Kubo HK, Verde PE, Krauspe R, Patzer T. A symptomatic medial synovial plica of the knee joint: an underestimated pathology in young patients. Arch Orthop Trauma Surg. 2019;139(11):1625-31.

17. Weckstrom M, Niva MH, Lamminen A, Mattila VM, Pihlajamaki HK. Arthroscopic resection of medial plica of the knee in young adults. Knee. 2010;17(2):103-7.

18. Schindler OS. The sneaky plica revisited: morphology, pathophysiology and treatment of synovial plicae of the knee. Knee Surg Sports Traumatol Arthrosc. 2014;22(2):247-62. 